\title{
SISTEM PREVENSI SCHOOL VIOLENCE DI MADURA BERBASIS GALTUNG CONFLICT TRIANGLE
}

\author{
Auliya Ridwan*
}

\begin{abstract}
A bstract: School violence may be understood as the threat or use of physical force with the intention to cause physical injury, damage of property or intimidation of another person at school. School violence is also violence that happens outside school as a result of a social interaction among the students. With regards to their prevention, many theories and propositions have been introduced including that of Conflict Triangle theory by $J$ ohan $\mathrm{G}$ altung. This paper is aimed at analyzing school violence in Madura by using this theory as a general framework of analysis. The paper will begin by providing a general overview of both the theory and the so-called carok tradition of Madura; a tradition of self-defense using traditional blade which often involves killing. U pon highlighting school violence in this island, the paper will then move on by suggesting that in order to delegitimize this violence, one must speak of preventive programs at practical level, and of deconstructing the cultural strength of carok tradition at the discursive one. We assume that once the carok tradition is being deconstructed, one would loose the cultural legitimacy of committing violence. In Madura violence is often legitimated by the culture and tradition of carok. To eradicate violence is therefore to get rid of carok tradition in the first place.
\end{abstract}

Keywords: school violence, carok, Galtung's Conflict Triangle, structural strength, cultural values

\section{Pendahuluan}

Kekerasan hampir terjadi di semua negara. Fakta-fakta di lapangan yang mencerminkan hal itu dapat dirinci dalam empat kategori, yaitu: (1) fakta-fakta yang mewakili masalah tawuran antar pelajar di Indonesia; (2) fakta-fakta yang mewakili school violence (kekerasan sekolah) mancanegara, yaitu Amerika Serikat dan Kanada; (3) fakta-fakta yang mewakili masalah bunuh diri di Indonesia; (4) fakta-fakta yang mewakili masalah kekerasan pada perspektif umum. ${ }^{1}$

Kekerasan dewasa ini bukan sekedar menyentuh dunia politik dan ekonomi belaka. Kekerasan kian merambah ke dunia pendidikan di seluruh belahan dunia termasuk Indonesia. Seiring pesatnya arus informasi "pesan-pesan" kekerasan dapat dengan mudahnya diterima oleh siapa saja dan di mana saja. $\mathrm{H}$ al ini menyebabkan kekerasan telah menjadi masalah global.

Kekerasan oleh pelajar di dunia pendidikan sebenarnya bukanlah barang kajian baru. Berbagai tindakan agresi pelajar berbentuk penyerangan-penyerangan fisik hingga penembakan terhadap rekannya sendiri telah kerap kali terjadi di negara-negara maju. Kasus Eric H arris (18) dan Dylan Klebold (17), dua pelajar Columbine High School di Littleton Colorado, Amerika Serikat, yang menewaskan 11 rekannya dan seorang guru, sebelum pada akhirnya mengakhiri aksinya dengan bunuh diri, pada 20 A pril 1999 tepat pada Adolf Hitler's Birthday, adalah sebuah contoh kecil dari sekian banyak kasus kekerasan yang belum terungkap. ${ }^{2}$

\footnotetext{
* Mahasiswa Program Magister Konsentrasi Shari'ah dan pemerhati pendidikan pada masyarakat Madura.

${ }^{1}$ Limas Sutanto, Ringkasan Proposal Disertasi, Kemanjuran Terapi Kedamaian, (Disampaikan di Ruang Sidang Program Pascasarjana Universitas Negeri Malang, tanggal 13 maret 2007).

${ }^{2}$ Helen Smith, The Scarred HeartUnderstanding and Identifying Kids Who Kill (Tennesse: Calisto Publishing, 2000 ), 9. Lihat juga Agus Surono/Shinta Teviningrum, Bahaya Tontonan Kekerasan pada Anak, www.balita-anda.indoglobal.com/ pdf. php?id=225.
} 
Kini masalah kekerasan pelajar mulai menjadi topik yang aktual di Indonesia. $\mathrm{Hal}$ ini diindikasikan dengan mulai maraknya liputan tentang berita kekerasan yang dilakukan oleh para pelajar. Contoh-contoh kekerasan pelajar ini setidaknya dapat diwakili pada kasus-kasus sebagai berikut: (1) penyerangan-penyerangan oleh geng motor di Kota Bandung pada awal tahun 2008; (2) aksi kekerasan geng pelajar putri (baca: Nero) dari Pati, J awa Tengah dan kasus serupa di Kota Malang; dan (3) kasus penjarahan swalayan oleh geng putri di Kediri, J awa Timur.

Kekerasan pelajar dewasa ini tidak hanya dilakukan oleh pelajar putra saja. Kekerasan pelajar juga dilakukan oleh pelajar putri. Nampaknya permasalahan kekerasan oleh pelajar putri menjadi masalah yang cepat tumbuh. Di lingkungan pendidikan sering kita jumpai tindakan kekerasan yang terkategorikan dalam tindakan kriminal. U mumnya kekerasan dalam kategori ini mengambil tindakan agresi atau offensive action (aksi yang telah dipersiapkan untuk menyerang), baik secara individual maupun kolektif. ${ }^{3}$

Masa-masa remaja pada pelajar pada umumnya ditandai dengan adanya keintiman dengan peer group (teman-teman sebaya). Pada masa ini remaja memilih lepas dari orang tua dan lebih intim dengan teman sebayanya. Perilaku sosial remaja ini disebut moding. ${ }^{4}$ Pada masa ini pula Remaja memiliki kecenderungan untuk mengikuti life style (gaya hidup) sebayanya. Bahkan nilai-nilai kelompok menjadi comformity (keterikatan sosialnya). Berawal dari keterikatan inilah ditambah dengan beberapa faktor negatif lainnya geng-geng pelajar yang destruktif dapat terbentuk. Misalnya dalam kategori kekerasan fisik adalah perilaku tawuran yang terjadi pada sekolah-sekolah umum, berbagai macam kekerasan fisik yang dikomite oleh geng-geng sekolah, dan masih banyak lagi insiden kekerasan yang terjadi di dalam sekolah yang tidak dipublikasikan. ${ }^{5}$

Masalah kekerasan yang dilakukan oleh para pelajar tentunya bukan semata-mata tanggung jawab keluarga, sekolah, dan atau masyarakat. Permasalahan ini adalah permasalahan yang kompleks dalam multiperspektif. Bagaimanapun sebuah tindakan kekerasan tentunya memiliki anteseden-anteseden tertentu. Dalam penelitian yang pernah dilaksanakan, peneliti menemukan faktor keluarga sebagai pemicu utama terjadinya kekerasan dan faktor pergaulan dengan teman sebaya sebagai katalisnya. ${ }^{6}$ Dunia pendidikan tidak boleh diam atas masalah kekerasan. Karena kekerasan, apapun antesedennya pasti berakibat destruktif terhadap aspekaspek sosial pelaku maupun korbannya.

Dalam perspektif behaviorisme dipercayai bahwa sifat-sifat manusia dibentuk oleh lingkungan. Dengan demikian sikap agresi sangat tergantung pada kondisi di luar (eksternal) yang menginginkan subyek tersebut untuk bersikap destruktif ataupun menyerang. Di sini, meminjam kaidah Box Skinner, dikatakan bahwa perilaku manusia itu lahir sebagai akibat upaya terus menerus secara trial and error, serta cenderung diulangi. Skinner dalam teori penguatan operannya menyatakan bahwa tingkah laku paling baik dapat diteliti dengan menyelidiki bagaimanakah tingkah laku itu berhubungan dengan peristiwa-peristiwa anteseden. Sehingga

\footnotetext{
${ }^{3}$ Abd. Rachman Assegaf, Pendidikan Tanpa Kekerasan (Yogyakarta: Tiara Wacana Yogya, Cet.I, 2004), 71.

${ }^{4}$ Arif A. Rofiq, Sistematika Psikologi Perkembangan Islami (Surabaya: Arkola, 2005), 62

${ }^{5}$ National Health and Education Concortium, Violence Againts Women: A National Report, (Washington DC., 1999).

${ }^{6}$ Auliya Ridwan, Skripsi: Identifikasi Kekerasan Pelajar di Kota Surabaya (Tipologi Kasus dan Kondisinya) (Surabaya: IAIN Sunan Ampel, 2007).
} 
menurut teori ini, maka kepribadian manusia itu diukur dari seberapa banyak perilaku itu diulangi. Meskipun demikian, hal ini tetap harus mengacu pada sikap terhadap nilai yang ingin dicapainya. Dan harus diingat bahwa ukuran perilaku behaviorisme itu bisa diamati.

A papun hipotesisnya, kekerasan oleh pelajar perlu mendapatkan perhatian secara tersistem yang dikomite oleh semua pihak yang concern terhadap dunia pendidikan. Pola-pola penanganan kekerasan tentunya sangat beragam tergantung dari kubutuhan sebuah lembaga berdasarkan aspek-aspek tertentu. Misalnya ITOP (Invitational Theory of Practice) yang merupakan teori untuk praktek komunikasi, menjaga pesan-pesan yang dikendaki secara ajeg untuk mengetahui, mengidentifikasi, dan merubah potensi-potensi destruktif. Sebagai langkah preventif terhadap terjadinya kekerasan dapat dimulai dari sekolah dengan program ini. ITOP pada pelaksanaannya, melibatkan peran sekolah dan lingkungan masyarakat secara bersamasama. $^{7}$

Dalam berbagai lembaga pendidikan terdapat banyak kasus-kasus kekerasan yang beragam jenisnya dan latar belakang kasusnya. Kondisi demikian menyebabkan terbentuknya sistem pencegahan school violence yang berbeda di satu lembaga dengan di lembaga yang lain. $\mathrm{Hal}$ ini disebabkan sistem yang digunakan bergantung pada banyak aspek seperti kondisi sosial, budaya, efektifitas, efisiensi, intensitas kasus, dan lain sebagainya.

Permasalahan school violence pada Masyarakat Madura membutuhkan sistem prevensi yang khusus. Ada dua alasan mengapa permasalahan ini perlu penanganan khusus, yaitu: (1) sistem preventif mampu menetralkan -atau paling tidak meminimalkan- intensitas kekerasan yang terjadi sebagai ekses benturan kelompok; (2) sistem preventif dapat mengidentifikasi akar permasalahan kekerasan yang terjadi. ${ }^{8} \mathrm{H}$ al ini tidak lepas dari pengaruh budaya Masyarakat Madura yang menjadikan carok sebagai cara membela harga diri. System of beliefs yang dijunjung tinggi Masyarakat ini adalah "Ango'a pote tolang tembeng pote mata" (lebih baik putih tulang dari pada putih mata) maksudnya lebih baik mati (membela harga diri) dari pada hidup menanggung malu. ${ }^{9}$ System of beliefs ini begitu kental apalagi pada masyarakat pedesaan. Kendati demikian masyarakat Madura adalah masyarakat yang menjunjung tinggi nilai-nilai religi khususnya Islam. Sehingga peranan seorang agamawan (guru agama/kyai) sangat berpengaruh pada masyarakat ini. Bahkan kewajiban berbakti kepada guru adalah menempati strata ke-2 setelah kewajiban kepada orang tua. Sedangkan kewajiban berbakti kepada pemerintah menempati strata ke-3. Sebagaimana dalam peribahasa bapa'babhu' guru rato (bapak-ibu, guru, ratu/pemerintah).

\section{Pengertian School Violence}

Kekerasan telah didefinisikan berbeda-beda oleh para pembuat teori penanganan

\footnotetext{
7 Stenley, "Using an Invitational Theory of Practice to Create Save and Succesfull Schools", dalam J ournal of Counseling and development (Virginia: American Counseling Assoociation, 2004), 302.

${ }^{8}$ Pada umumnya school violence ditangani setelah terjadi. Penanganan semacam ini sebagian besar terkonsentrasi pada solusi untuk penyelesaian konflik tetapi kurang terkonsentrasi pada akar-akar permasalahan konflik. Hal ini menyebabkan terjadinya kekerasan yang sama oleh pelaku yang sama berpotensi terjadi kembali.

${ }^{9}$ System of beliefs merupakan ujaran-ujaran tertentu yang merepresentasikan perspektif psikososial masyarakat tertentu terhadap sebuah permasalahan. Kendati demikian, system of beliefs tidak selalu diujarkan. Nilai-nilai yang melekat pada diri sebuah kelompok masyarakat juga dikategorikan sebagai System of beliefs.
} 
kekerasan dan peneliti. Ringkasnya, Elliot, Hamburgh, dan William mendefinisikan kekerasan sebagai segala bentuk sikap, perilaku yang berbentuk ancaman, intimidasi, yang membuat orang lain menderita.

...the threat or use of physical force with the intention of causing of physical injury, damage or intimidation of another person. ${ }^{10}$

Kekerasan juga berarti hal yang dengan sengaja dilakukan sehingga menyebabkan luka secara fisik pada orang lain atau menyebabkan kerusakan pada lingkungan.

...Violence here refers to willful phisical injury of another person or to the damage or destruction of property. ${ }^{11}$

Dari dua pengertian di atas dapat disimpulkan bahwa kekerasan adalah segala bentuk sikap atau perilaku yang membuat orang lain menderita dan atau menyebakan kerusakan pada lingkungan.

Sedangkan School violence adalah segala aktivitas kekerasan yang terjadi di sekolah dan atau merupakan ekses dari interaksi siswa-siswa atau siswa-guru di sekolah.

Secara umum kekerasan meliputi tindakan kriminal dan perilaku anti sosial. Sebagaimana dikemukakan oleh Futrel, H oward, Flora, dan G riffin:

... definition of violence, which include delinquent and antisocial behaviour... ${ }^{12}$

Daniels, Arredondo, dan D'Andrea membagi kekerasan menjadi enam kategori, yaitu: ${ }^{13}$ kekerasan fisik (physical violence), kekerasan seksual dan gender (sexual and gender violence), kekerasan media (media violence), kekerasan budaya dan rasial (cultural and racial violence), kekerasan politik-ekonomi (political-economic violence), dan kekerasan atas diamnya seseorang manakala ia melihat kekerasan terjadi (violence of silence) ${ }^{14}$.

Dalam kajian ini kajian sistem prevensi school violence dibatasi pada kekerasan fisik (physical violence), kekerasan budaya dan rasial (cultural and racial violence), dan kekerasan atas diamnya seseorang manakala ia melihat kekerasan terjadi (violence of silence). Hal ini dikarenakan jenis-jenis kekerasan tersebut merupakan hal yang paling umum ditemui dalam kasus-kasus school violence di Madura.

\section{Madura dan Kekerasan}

Kekerasan dalam budaya Madura pada umumnya selalu timbul karena perasaan maloh (malu) atau terhina pada diri pelakunya karena harga dirinya dilecehkan orang lain. ${ }^{15}$ Perasaan inilah yang kemudian menjelma menjadi sebuah ritual carok (berkelahi dengan senjata tajam). Masalah harga diri menjadi sangat penting bagi Masyarakat Madura. Untuk mengembalikan

${ }^{10}$ Michael D'Andrea, "Comprehensive School-B ased Violence Prevention Training: A Developmental Ecological Training Model", dalam J ournal of Counseling and Development(Virginia: American Counseling Association, 2004), 278.

${ }^{11}$ McKinney, et.al., Developmental Psychology, (Illinois: The Dorsey Press, 1977), 184.

12 Michael D'Andrea, Comprehensive... 278.

${ }^{13}$ Ibid., 278-279.

$14 \mathrm{Ibid}$.

${ }^{15}$ Malo secara bahasa dapat diartikan dengan malu. Padanan kata ini dalam Bahasa Madura adalah Todus. Tapi secara makna malo berarti merasa terhina karena kapasitas dirinya didak diakui atau dilecehkan orang lain. Sedangkan todus berarti malu karena melanggar peraturan secara normatif. Latif Wiyata, Carok Konflik Kekerasan dan $\mathrm{H}$ arga diri O rang Madura (Yogyakarta: LKiS, Cet. II, 2006), 170. 
harga diri tidak ada jalan lain kecuali melakukan tindakan ekstrim (pembunuhan) terhadap orang yang melecehkan. Sebuah ungkapan "Ango'a pote tolang tembeng pote mata" memberikan indikasi sangat kuat tentang hal itu. ${ }^{16}$

Dalam Masyarakat Madura ada dua golongan yang memiliki pengaruh besar dalam masyarakat, yaitu Kyae dan Blater. ${ }^{17}$ Dalam banyak kasus kekerasan yang dilakukan oleh pelaku carok -baik yang telah dikategorikan Blater sebelumnya atau tidak- Kyae memiliki peran yang besar dalam mendamaikan kedua belah pihak yang bertikai agar tidak terjadi carok balasan. Tentunya upaya ini juga didampingi oleh aparat pemerintahan (umara'y.

Dalam pengamatan penulis, nilai-nilai carok yaitu membela harga diri terekam sangat kuat pada diri orang Madura, bahkan yang seusia pelajar sekolahpun. Kendati pelajar di sekolah tidak sampai melakukan pembunuhan tetapi nilai-nilai carok memainkan peran yang sangat kuat dalam terjadinya konflik. Hal ini tentunya memerlukan penanganan yang tidak hanya melibatkan seluruh elemen sekolah tetapi juga Kyae dan aparat hukum dalam menyelesaikan konflik. Hal ini dipandang sangat urgen karena ikatan kelompok dalam masyarakat ini yang sangat kuat sangat memungkinkan terjadinya konflik lanjutan yang melibatkan massa yang lebih besar dari kedua pihak yang bertikai.

Selain itu dalam Budaya Madura juga dikenal istilah Ejhin yaitu tidak ikut campur urusan orang lain. Sehingga pada saat carok berlangsung ataupun sesudahnya masyarakat sekitar tidak mau ikut campur urusan kedua pihak yang bertikai. Dari sinilah semakin memperkuat peran Kyae dan aparat hukum untuk mendamaikan carok.

\section{Galtung's Conflict Triangle}

Permasalahan di atas dapat dikaji dalam terminologi "G altung conflict triangle" atau "the violence triangle".$^{18} \mathrm{G}$ altung memetakan tipe-tipe kekerasan secara umum menjadi tiga kategori: direct violence (behavioral), cultural violence (social constructs) dan structural violence. Masing-masing dari kategori merepresentasikan masing-masing sudut dari the violence triangle (segitiga kekerasan), yang oleh $\mathrm{G}$ altung dijelaskan dalam built-in vicious cycles (struktur bagian siklus kekerasan). Galtung membagi struktur ini ke dua kategori, yaitu visible (nampak/kongkrit) dan invisible (tak nampak/abstrak) (Gambar 1):
visible
direct
violence
invisible
cultural
structural
violence
violence

\section{Segitiga Konflik Galtung (Gambar 1)}

\footnotetext{
${ }_{16}$ Ibid. 172.

${ }^{17}$ Kyae yaitu kiai atau pemuka Agama Islam dan B latèr sebagaimana disebutkan oleh Latif Wiyata sebagai seseorang yang perilakunya cenderung mengarah ke tindakan kriminalitas. Kendati demikian penulis memiliki persepsi yang berbeda dengan Latif Wiyata. Menurut penulis B latèr tidak selalu orang yang melakukan kriminalitas tetapi juga mantan pelaku kriminalitas (insyaf) juga dikategorikan sebagai B latèr.

${ }^{18}$ Sebuah model teori yang dikembangkan oleh seorang peneliti asal Norwegia, J ohan G altung, yang menganalisa
} 
Berdasarkan Galtung: efek visible (nampak) dari direct violence (kekerasan langsung) dapat diketahui, seperti: pembunuhan, melukai, pemindahan properti, perusakan material, dan semua bentuk penyerangan terhadap warga yang semakin meningkat. Tetapi efek invisible dapat terjadi lebih menyakitkan, yaitu bentuk kekerasan langsung yang memperkuat kekerasan struktural dan kultural. ${ }^{19}$

Galtung mengklaim meskipun aspek kultural dan struktural tidak nampak, dalam faktanya memainkan peran yang sangat penting selama masa pencegahan dan rehabilitasi konflik. la menyatakan bahwa kekerasan kultural dan struktural menyebabkan kekerasan langsung yang melibatkan aktor kekerasan yang memicu kekerasan struktural dengan menggunakan kultur untuk melegitimasi penggunaan kekerasan sebagai instrumen yang dapat digunakan. Dengan menggunakan teori ini maka kekerasan yang terjadi pada obyek yang diteliti dapat dikaji tidak sekedar dari aspek yang nampak saja, tetapi juga dari aspek yang tak nampak di mana aspek ini memiliki peran besar dalam melegitimasi bagi terjadinya kekerasan sebagai sebuah instrumen.

\section{Aplikasi Prevensi School Violence Berbasis Galtung Conflict Triangle}

Berdasarkan teori $G$ altung, direct (behavioral) violence yang mungkin terjadi di sekolah adalah perkelahian individual, perkelahian kelompok, bahkan carok. Sedangkan struktural yang ada yaitu sekolah dan masyarakat. Masalah kultur merupakan yang paling kompleks karena Budaya Madura "melegitimasi" carok untuk membela harga diri. Prevensi school violence di Madura dapat dilakukan dengan jalan memanfaatkan potensi struktural sekolah dan masyarakat guna meminimalkan potensi konflik. Sehingga potensi struktural tidak dimanfaatkan oleh aktor kekerasan untuk melegitimasi konflik dengan nilai-nilai budaya melalui stuktur yang ada.

Aspek struktural di sekolah adalah seluruh komponen sekolah (mulai kepala sekolah hingga siswa) yang berkaitan erat dengan masalah kekerasan. Kepala sekolah bertugas membagun hubungan dengan masyarakat guna menjalin kerjasama dalam rangka prevensi dan membangun sistem komunikasi sehingga dapat mengidentifikasi potensi-potensi dari luar yang mendukung terjadinya school violence seperti kelompok pemuda yang salah satu anggota kelompoknya ada di sekolah itu. $\mathrm{H}$ al ini dikarenakan kebanyakan konflik kekerasan yang terjadi tidak hanya berhenti pada diri pelaku yang bertikai, tetapi juga melibatkan orang-orang di sekitarnya untuk melakukan aksi serupa dengan jumlah massa yang besar. Selain itu juga kepala sekolah juga harus melakukan pendekatan personal agar terbangun hungungan emosional dengan orang di luar sekolah yang memiliki pengaruh besar (utamanya Blater). $\mathrm{Hal}$ ini dikarenakan pada Masyarakat Madura orang akan enggan melakukan sesuatu yang merugikan kepada orang yang dikenalnya dengan baik apalagi sudah merasa sebagai saudara sendiri. Dari sinilah upaya meminimalkan bahkan menetralisir konflik kekerasan dimulai.

penyebab violence kekerasan) dalam tiga fase: before violence (sebelum kekerasan terjadi), during violence (pada saat kekerasan terjadi), dan after violence (setelah kekerasan terjadi).

${ }^{19}$ The visible effects of direct violence are known: the killed, the wounded, the displaced, the material damage, all increasingly hitting the civilians. But the invisible effects may be even more vicious: direct violence reinforces structural and cultural violence. J ohan Galtung, Violence, War, and Their Impact: On Visible and Invisible Effects of Violence, (Polylog: Forum for Intercultural Philosophy 5, 2004). Tersedia secara online dalam http://them.polylog.org/5/fgjen.htm. Untuk studi lebih komprehensif dapat ditemukan di www.transcend.org/TRRECBAS.HTM 
Pendekatan lain yang harus dilakukan adalah kepada para kyae. Dengan jalan ini kyae akan melakukan pendekatan kepada masyarakat dan memberikan pengertian bahwa penyelesaian konflik dengan kekerasan apalagi menggunakan pembunuhan, sama sekali tidak dilegitimasi oleh Islam. Karena dalam Islam sendiri diajarkan bahwa seorang muslim dengn muslim lainnya adalah saudara.

Pendekatan ke luar sekolah yang lain adalah melalui para penegak hukum. Artinya tindakan hukum berkenaan dengan pelaku kekerasan tidak bisa ditolelir lagi dan diberikan hukuman yang seberat beratnya. Hal ini untuk memberikan pengalaman kepada seluruh siswa dan masyarakat agar percaya kepada hukum positif.

Pembinaan dalam ruang lingkup sekolah dilakukan oleh staf-staf tertentu, misalnya konselor dan guru agama yang memiliki pengaruh besar terhadap siswa. Kendati demikian tanggung jawab pembinaan kepada siswa akan nilai-nilai anti kekerasan juga merupakan tanggung jawab seluruh guru dan staf. Dengan jalan ini maka school violence dapat diminimalkan bahkan dinetralkan potensi terjadinya. Bahkan pada saat terjadinya pun akan banyak mendapat tantangan baik dari dalam sekolah maupun pihak di luar sekolah. Artinya bahwa membela harga diri dengan jalan kekerasan sudah tidak didukung oleh struktur yang ada. Karena legitimasi kekerasan oleh budaya tidak mungkin dapat berjalan tanpa ada aktor yang menggerakkan kekuatan struktural untuk melegitimasi penggunaan budaya itu sendiri.

\section{Daftar Rujukan}

Arif A. Rofiq, Arif A. Sistematika Psikologi Perkembangan Islami. Surabaya: Arkola, 2005.

Assegaf, Abd Rachman. Pendidikan Tanpa Kekerasan. Yogyakarta: Tiara Wacana Yogya, 2004. D'Andrea, Michael. Comprehensive School-Based Violence Prevention Training: A

Developmental Ecological Training Model, dalam J ournal of C ounseling and Development, Virginia: American Counseling Association, 2004.

J ohan Galtung, J ohan. Violence, War, and Their Impact: On Visible and Invisible Effects of Violence, Polylog: Forum for Intercultural Philosophy dalam http://them. polylog.org/5/fgjen.htm. dan www.transcend.org/TRRECBAS.HTM

Latif Wiyata, Latif. Carok Konflik Kekerasan dan Harga diri O rang Madura. Yogyakarta: LKiS, 2006.

Limas Sutanto,Limas. Ringkasan Proposal Disertasi, Kemanjuran Terapi Kedamaian, Malang: PPs Universitas Negeri Malang, 2007.

McKinney, et.al. Developmental Psychology. Illinois: The Dorsey Press , 1977.

National Health and Education Concortium. Violence Againts Women: A National Report. Washington DC, 1999.

Ridwan, Auliya. Skripsi: Identifikasi Kekerasan Pelajar di Kota Surabaya (Tipologi Kasus dan Kondisinya).Surabaya: IAIN Sunan Ampel,

Rifai, Mien Ahmad. Manusia Madura: Pembawaan, Perilaku, Etos Kerja, penampilan, dan Pandangan Hidupnya seperti Dicitrakan Peribahasanya, Yogyakarta: Pilar Media, 2007. 
Surono, Agus \& Shinta Teviningrum. Bahaya Tontonan Kekerasan pada Anak, www.balitaanda.indoglobal.com/pdf.php?id $=225$

Smith, H elen. The Scarred Heart Understanding and Identifying Kids Who Kill. Tennesse: Calisto Publishing, 2001.

Stenley. Using an Invitational Theory of Practice to Create Save and Succesfull Schools, dalam J ournal of Counseling and development. Virginia: American Counseling Assoociation, 2004. 